\title{
Morbidity and Mortality Statistics in Paediadric Medical Ward of Bingham University Teaching Hospital, Jos
}

\author{
Shehu Maryam*, Davou Kaneng Nyam, Ubanyi Tina Onyeka, Mava Yakubu, Eseigbe Edwin Ehi, \\ Yakubu Alhassan Mela
}

Department of Paediatrics, Bingham University Teaching Hospital, Jos, Nigeria

Email address:

maryamshehu1405@gmail.com (S. Maryam)

${ }^{*}$ Corresponding author

To cite this article:

Shehu Maryam, Davou Kaneng Nyam, Ubanyi Tina Onyeka, Mava Yakubu, Eseigbe Edwin Ehi, Yakubu Alhassan Mela. Morbidity and Mortality Statistics in Paediadric Medical Ward of Bingham University Teaching Hospital, Jos. American Journal of Internal Medicine. Vol. 7, No. 3, 2019, pp. 51-55. doi: 10.11648/j.ajim.20190703.11

Received: May 6, 2019; Accepted: June 3, 2019; Published: June 12, 2019

\begin{abstract}
Background: Approximately seventy-five percent of the deaths that occur in children excluding neonatal deaths in sub-Sahara Africa result from preventable and curable diseases like pneumonia, diarrhea and malaria. A hospital-based mortality and mortality pattern can be used to appraise the demographic profile and burden of disease in a community. AIM: To determine the morbidity and mortality pattern of children admitted into the PMW of BHUTH, Jos. Methodology: This was a retrospective study. Admissions into the paediatric medical ward of Bingham University Teaching hospital, Jos between October 2017 to Octorber 2018 were reviewed, with data from the admission and discharge records of the ward. Data was analyzed using SPSS version 20. A p value $<0.05$ was considered statistically significant. Ethical clearance was gotten from the ethical committee of the hospital. Results: A total of 357 children aged 1 month-15 years were admitted over the study period, of these, $189(52.9 \%)$ were males, and $168(47.1 \%)$ were females with a male:female ratio of 1.1:1. The age range was 1-168 months. Two hundred and twenty-seven (63.6\%) of the children were under 5 years old. The major cause of mortality in children less than 5 years of age were BPN, Sepsis and malaria with $2(18.2 \%)$ each respectively. The cause of morbidity was majorly due to malaria $70(20.2 \%)$, followed by various crisis of SCA $42(12 \%)$. The highest case fatality rate was from viral haemorrhagic fever (VHF) with 28\%, followed by Acute bacterial meningitis (ABM) and Protein energy malnutrition (PEM) with complications each having $15.4 \%$ respectively. The length of hospital stay was inversely proportional to mortality and the difference was statistically significant $\left(\chi^{2}=24.58, \mathrm{p}<0.00\right)$. The trend of sex distribution and morbidities showed that the month with the highest morbidity was in October 2017 with 44 admissions, the highest number of male morbidities was in January, 2018 with 26 males, while the month with the highest number of morbidities for females was in October 2017 with 21 patients. Out of all the 357 admissions, (92.7\%) were discharged, (2.2\%) left against medical advice, $(0.6 \%)$ were referred, while $(4.5 \%)$ died. Conclusion: The burden of paediatric morbidity and mortality is on children under 5 years and the causes are mainly preventable. An emphasis and focus on malaria eradication, vaccination and other child survival strategies will help to reduce childhood morbidity and mortality.
\end{abstract}

Keywords: Paediatric, Morbidity, Mortality, Medical, Jos

\section{Introduction}

About $28 \%$ of the total world population is made up of children that are less than 15 years of age [1]. The World Health Organization documented that about half of the total deaths in Africa is found in children younger than 14 years [2]. About 4.6 million childhood deaths occur every year [3].
More than 26,000 children under the age of five die around the world every day, mostly from preventable causes [4]. Child mortality is a sensitive indicator of a country's development and telling evidence of its priorities and values, therefore it was a good thing when childhood mortality rates dropped from 11.9 million deaths to 7.7 million deaths from 1990 to $2010[3,5]$.

The under- five mortality rates in the world was more in 
sub-Sahara Africa, with $50 \%$ occurring in the region, followed by south Asia with $33 \%$ and with less than $1 \%$ occurring in the developed countries [6]. Approximately seventy-five percent of the deaths that occur in children excluding neonatal deaths in sub-Sahara Africa result from preventable and curable diseases like pneumonia, diarrhea and malaria [7].

Childhood morbidity and mortality in developing countries are high. A Large-scale data reporting of paediatric morbidity and mortality in developing countries done by Duke et al documented that majority of the cause of deaths were from infectious diseases [8]. A number of studies done in Nigeria reported that children suffer from various infectious and vaccine preventable diseases leading to significant morbidity and mortality [9-13]. The most common childhood killers have been identified to be Pneumonia, diarrhoea, malaria, measles, malnutrition, tuberculosis, and human immune deficiency virus [8].

The increasing number and degree of childhood morbidity and mortality are aggravated by different factors, like delay in seeking medical treatment, poverty, unsafe drinking water, poor sanitation, inadequate hygiene, diarrhea, and poor nutritional status [14-15]. Childhood mortality in paediatric departments is commonly caused by preventable infectious and reversible diseases, so urgent treatment and resuscitation are the key in reducing poor outcomes [16]. Early diagnosis and treatment of pneumonia, sepsis, malaria, and diarrheal diseases has been shown to reduce childhood mortality in acute pediatric hospitals [17-18].

A hospital-based mortality and mortality pattern can be used to appraise the demographic profile and burden of disease in a community. Information obtained from the review will be helpful in assessing and re-evaluating existing services and in improving facilities and patient care [19-20]. This study was carried out to determine the morbidity and mortality pattern of children admitted into the PMW of BHUTH, Jos.

\section{Methodology}

This was a retrospective cross- sectional descriptive study from October 1, 2017 to October 31, 2018. The case files of all children aged one month to 14 years admitted into the paediatric wards as recorded in the ward register, were reviewed. Neonatal and surgical cases were excluded from the study. Data retrieved from the case files included age, gender, diagnosis and duration of hospitalization. Data collected was entered into a spread sheet using SPSS 20.0 for Windows ${ }^{\circledR}$ statistical software which was also used for analysis. Descriptive statistics was used to analyze the obtained data.

\section{Results}

A total of 357 children were admitted over the study period, of these, $189(52.9 \%)$ were males, and $168(47.1 \%)$ were females with a male: female ratio of 1.1:1. Mean age was $59.06 \pm 51.16$ months, with the youngest 1 month old, and the oldest 168 months old (14 years). Two hundred and twenty seven $(63.6 \%)$ of the children were under 5 years, of which majority were males as shown in Table 1.

Table 1. Age and Gender Distribution of the Children.

\begin{tabular}{llll}
\hline Age & Male $\boldsymbol{n}(\boldsymbol{\%})$ & Female $\boldsymbol{n}(\boldsymbol{\%})$ & Total $\boldsymbol{n}(\boldsymbol{\%})$ \\
\hline$<$ 5 Years & $124(34.7)$ & $103(28.9)$ & $227(63.6)$ \\
$>$ 5 Years & $65(18.2)$ & $65(18.2)$ & $130(36.4)$ \\
Total & $189(52.9)$ & $168(47.1)$ & $357(100)$ \\
\hline
\end{tabular}

Table 2 shows the top seven diagnosis were malaria, sickle cell anaemia (SCA), Acute diarrhoeal disease (ADD), URTI, Sepsis, Typhoid fever and Pneumonia respectively. Other Reportable infectious cases like Viral haemorrhagic fever, $\mathrm{TB}$, Measles and acute flaccid paralysis were also seen.

Table 2. Diagnosis and frequency.

\begin{tabular}{|c|c|c|}
\hline Diagnosis & Frequency & Percentage \\
\hline Malaria & 72 & 20.2 \\
\hline SCA & 43 & 12.1 \\
\hline ADD & 28 & 7.8 \\
\hline URTI & 25 & 7.0 \\
\hline Sepsis & 25 & 7.0 \\
\hline Typhoid fever & 23 & 6.4 \\
\hline Broncho Pneumonia & 21 & 5.9 \\
\hline Febrile Convulsion & 20 & 5.6 \\
\hline Protein Energy Malnutrition & 13 & 3.6 \\
\hline Acute Bacterial Meningitis & 13 & 3.6 \\
\hline Urinary tract infection & 12 & 3.4 \\
\hline Viral haemorrhagic fever & 7 & 2.0 \\
\hline Tuberculosis & 6 & 1.7 \\
\hline Acute glomerulonephritis & 5 & 1.4 \\
\hline Nephrotic syndrome & 4 & 1.1 \\
\hline Food poisoning & 3 & 0.8 \\
\hline Severe Anaemia & 3 & 0.8 \\
\hline Bronchial Asthma & 3 & 0.8 \\
\hline PUD & 2 & 0.6 \\
\hline Diabetes Mellitus & 2 & 0.6 \\
\hline Rheumatic Fever & 2 & 0.6 \\
\hline Nephroblastoma & 2 & 0.6 \\
\hline Aspiration Pneumonitis & 2 & 0.6 \\
\hline Acute flaccid paralysis & 2 & 0.6 \\
\hline Measles & 1 & 0.3 \\
\hline Hiv/Aids & 1 & 0.3 \\
\hline Others & 17 & 4.8 \\
\hline Total & 357 & 100 \\
\hline
\end{tabular}

The proportion of the under- five mortality is $68.8 \%$ as against $31.2 \%$ for those above the age of five years as depicted in table 3 .

Table 3. Age and Sex Distribution of the Mortalities.

\begin{tabular}{llll}
\hline Age & Male $\boldsymbol{n}(\boldsymbol{\%})$ & Female $\boldsymbol{n}(\boldsymbol{\%})$ & Total $\boldsymbol{n}(\boldsymbol{\%})$ \\
\hline$<5$ Years & $6(37.4)$ & $5(31.4)$ & $11(68.8)$ \\
$>$ 5 Years & $2(12.6)$ & $3(18.6)$ & $5(31.2)$ \\
Total & $8(50.0)$ & $8(50.0)$ & $16(100.0)$ \\
\hline
\end{tabular}

The causes of death in under- fives are shown in Table 4. Pneumonia, Sepsis and severe Malaria were the commonest cause of death with each having $18.2 \%$ respectively. 
Table 4. Causes of Mortality in Children Under the Age of 5.

\begin{tabular}{lll}
\hline Diagnosis & Frequency $(\boldsymbol{n})$ & Percentage \\
\hline Sepsis & 2 & 18.2 \\
Severe BPN & 2 & 18.2 \\
Severe Malaria & 2 & 18.2 \\
PEM & 2 & 18.2 \\
VHF & 1 & 9.1 \\
Diarrhoeal Disease & 1 & 9.1 \\
AKI & 1 & 9.1 \\
Total & 11 & 100 \\
\hline
\end{tabular}

The causes of death in children above the age of 5 years are shown in Table 5. Meningitis had the highest percentage with $40 \%$.

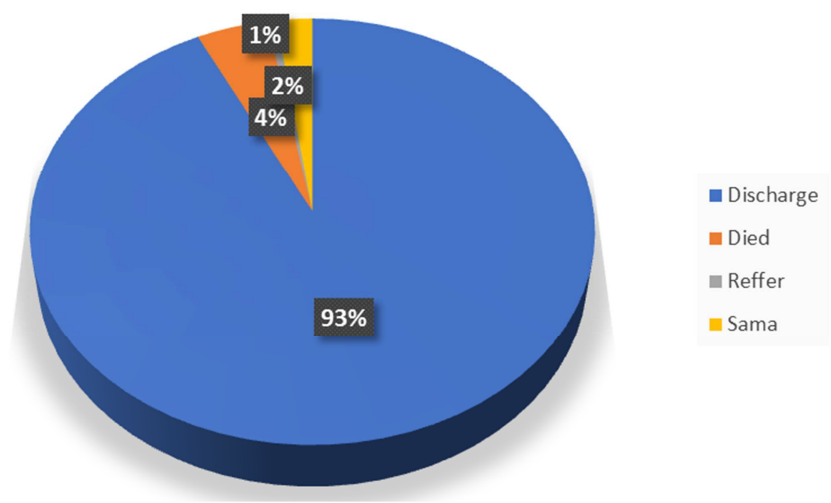

Figure 1. Outcome of Hospital admissions.

Table 5. Causes of Mortality in Children > 5 Years of age.

\begin{tabular}{lll}
\hline Diagnosis & Frequency $(\boldsymbol{n})$ & Percentage \\
\hline Meningitis & 2 & 40.0 \\
Sepsis & 1 & 20.0 \\
Severe BPN & 1 & 20.0 \\
\hline
\end{tabular}

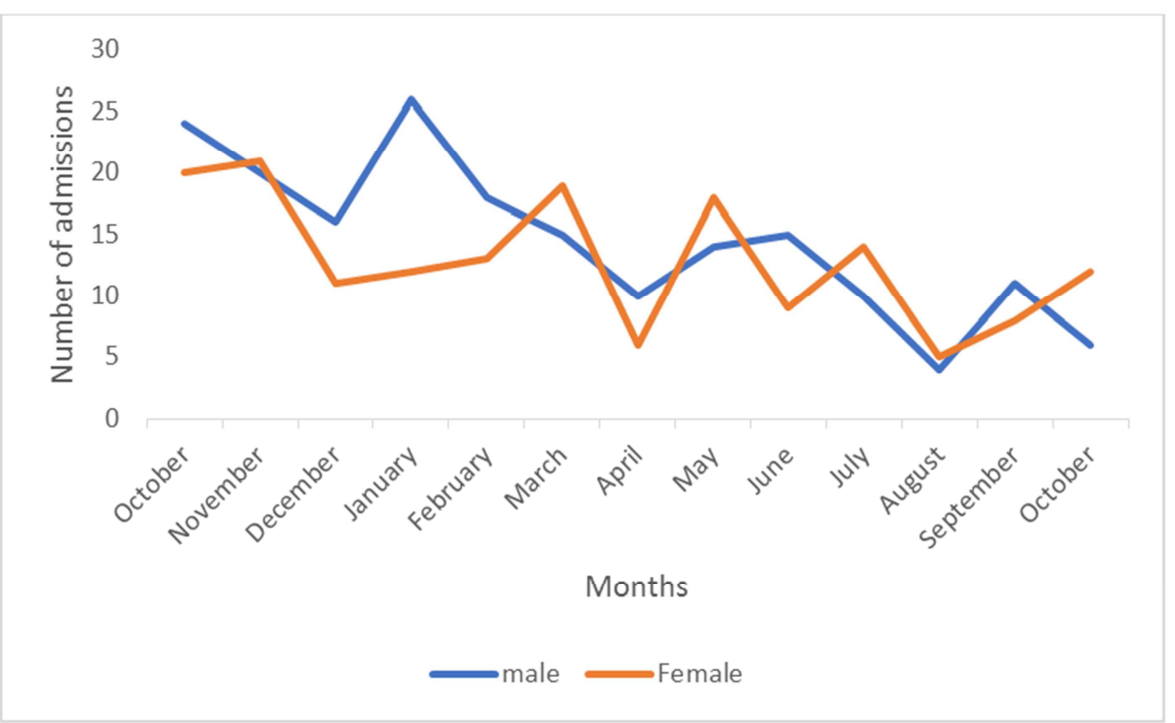

Figure 2. Trend of sex distribution of morbidities in BHUTH from October 2017 to October 2018.

\section{Discussion}

There was a male preponderance in total admission seen in the Paediatric medical ward of BHUTH, Jos. This could

\begin{tabular}{lll}
\hline Diagnosis & Frequency $(\boldsymbol{n})$ & Percentage \\
\hline VHF & 1 & 20.0 \\
Total & 5 & 100 \\
\hline
\end{tabular}

About $93 \%$ of the total admissions were discharged, $4 \%$ died and $2 \%$ of the patients signed against medical advice. Only $1 \%$ of the patient were referred.

The case fatality rate was highest in Viral hemorrhagic fever with $28.6 \%$, followed by acute bacterial meningitis and PEM with $15.4 \%$ respectively, while severe malaria had the least with $2.8 \%$.

Table 6. Diagnosis and Case Fatality Rate.

\begin{tabular}{llll}
\hline Diagnosis & Total number & Mortality & CFR (\%) \\
\hline VHF & 7 & 2 & 28.6 \\
Meningitis & 13 & 2 & 15.4 \\
PEM & 13 & 2 & 15.4 \\
Severe BPN & 21 & 3 & 14.3 \\
Sepsis & 25 & 3 & 12.0 \\
ADD & 28 & 1 & 3.6 \\
Severe Malaria & 72 & 2 & 2.8 \\
\hline
\end{tabular}

The length of stay was inversely proportional to mortality. Majority of the mortality took place within 72 hours of admission. There was a significant difference between the number of mortality and the length of stay $\left(\chi^{2}=24.58, \mathrm{p}<0.00\right)$.

Table 7. Mortality and Duration of Admission.

\begin{tabular}{ll}
\hline Duration of Admission (hours) & Mortality (\%) \\
\hline$<72$ hours & $14(87.5)$ \\
$>72$ hours & $2(12.5)$ \\
Total & $16(100)$ \\
\hline
\end{tabular}

Months

because of the demographic population, the increased biological vulnerability of males to infection or because males are believed to be more important than females and so when they are sick, medical help is sought for them quickly than the females. This result is comparable to what was 
obtained by Toma et al in Jos [12], Abhulimhen-Iyoha in Benin [10], Garba et al in Gusau [21] and Anyanwu et al in Abakaliki [13]. Other studies done by Adhikeri et al in Nepal [22] and Gordon et al [23] in Ethiopia also had male preponderance.

Children less than 5 years of age contributed to about $65 \%$ of the total admission, this could be explained by the low immunity against infectious diseases in this age group, making them susceptible to infections. This is similar to other studies done all over Nigeria and outside the country [10, 12, $8,21-24]$.

Infectious diseases like Malaria, Acute diarrhoeal disease, Upper respiratory tract infections, Sepsis, Typhoid fever and Broncho pneumonia were the major causes of morbidity. Although Sickle cell anaemia which is an autosomal recessive haematological disease was the second highest cause of admission, they all came as a result of various crises which were mostly precipitated by infectious diseases, this is similar to what was obtained by toma et al in Jos [12]. The high morbidity pattern from infectious disease like malaria, URTI, ADD, Typhoid fever shows the need for more control and eradication measures against malaria, the need to strengthen our immunization programme and sanitation measures. The result is comparable to what was obtained by Toma et al in Jos [12] and Garba et al in Gusau [21]. Respiratory tract infections and acute diarrhoeal diseases accounted for very high number of morbidity in this study, which is similar to what was obtained in study done in Benin [10], Osogbo [11], Ababkaliki [13], Ethiopia [23], Nepal [22] and Papua-New Guinea [8].

The over all mortality rate in BHUTH was $4.5 \%$. The under- five mortality rate was $3.1 \%$ which was higher than those greater than five years old with the mortality rate of $1.4 \%$. This could be explained by the vulnerability of those under five. The causes of mortality in under-fives and over five- year old children were infectious diseases; however, PEM was a major cause of death that was seen in the underfives but not in those above five years old. A plausible explaination is because PEM is a disease of under-fives. The mortality rate is lower than that obtained in other studies around Nigeria where the mortality rate ranged between $6.5 \%-12.6 \%[21,13,24-26$, ]. The reason for this could be because of the location and difference in age range and Paediatric units included. The mortality rate in Nigeria was similar to that obtained in the different hospitals in PapauNew Guinea, which ranged between $1 \%-11 \%$, while in Ethiopia the mortality rate was about $10 \%[8,23]$.

The major cause of mortality in under-fives were Sepsis, severe BPN, Malaria and PEM, while in those above five years of age ABM was the major cause of death. The absence of PEM being a cause of death in those above five years of age is due to the fact that PEM is a disease of under-five. Malaria was also not a cause of mortality in those older than five years old, the reason could be because they have developed some level immunity against malaria. This is similar to what was obtained in other studies were Sepsis, Malaria, Meningitis, Pneumonia and PEM accounted for most of the mortalities [10-13, 21]. However, this is in contrast to what was obtained by George et al and Chukwu et al were HIV and Malignancies were the major cause of mortality respectively $[20,24]$. It is of worthy to note that VHF was also a cause of mortality in this study. This is expected as BHUTH serves as a referring center for VHF (Lassa).

Viral haemorrhagic fever had the highest CFR in this study. A plausible explanation is because, it's a documented fact that VHF have very high case fatality rate [27]. Acute bacterial meningitis and PEM also had high case fatality rate. This is comparable to what was obtained by Toma et al and Duru et al $[12,28]$. This is in constrast to what was obtained by Chukwu et al in Enugu, where Tetanus had the highest CFR., [10] severe PEM had a similar CFR 28.7\%, to that of the current study.

The duration of hospital stay was inversely related to mortality. This could be because the first 24-48hrs of admission are crucial to the survival of patients. It could also be because of late presentation due to poor health seeking behavior. In the study done by Gordon et al, about one third of the mortalities occurred within $24 \mathrm{hrs}$ of admission.

The dry (harmattan) season (October-February) had the highest number of admissions compared to the raining and hot season. This could be because of the high rate of morbidity from Malaria, which is said to peak between October to January [13, 23].

\section{Conclusion}

The morbidity and mortality pattern found in the PMW of BHUTH Jos, showed that infectious diseases such as Malaria, Pneumonia, Acute Bacterial Meningitis and Sepsis are the major cause of Morbidity and Mortality in the Hospital. Viral haemorrhagic fever had the highest case fatality rate. Non-communicable diseases like PEM and SCA also account for a lot of morbidity and mortality.

The morbidity and the mortality burden are more in children younger than the age of 5 years, reflecting the need for improvement on health programmes like child survival strategies and integrated management of childhood illness (IMCI) that is directed towards children less than five years old. More health education and enlightment campaign environmental sanitation and good hygiene.

Therefore, there is the need to improve on immunization coverage and child survival strategies and integrated management of childhood diseases in the state. Health educational programs on child-hood nutrition and how to prevent SCA needs to be intensified.

\section{References}

[1] Bonita FS, Richard EB. Overview of Pediatrics: In kligeman RM, Behrman RE, Schor NF, St. Geme 111 JW and Santon BF. Nelson Textbook of Pediatrics. 19 ed. Philadelphia: W. B. Saunders Company; 2011: 1-13. 
[2] Mathers CD, Boerma T, Fat DM. Global and regional causes of death. Br Med Bull 2009; 92: 7-32.

[3] Rajaratnam JK, Marcus JR, Flaxman AD, Wang H, LevinRector A, Dwyer L, et al. Neonatal, postneonatal, childhood, and under-5 mortality for 187 countries, 1970-2010: a systematic analysis of progress towards millennium development goal 4. Lancet. 2010; 375 (9730): 1988-2008.

[4] Black RE, Morris SS, Bryce J. Where and why are 10 million children dying each year? The Lancet. 2003; 361: 2226-2234.

[5] Park K. Indicators of health. In: Park K, ed. Park's Textbook of Preventive and Social Medicine. 17th ed. Jabalpur, India: M/S Banarsidas Bhanot Publishers. 2002; p21-24.

[6] Organization WH. World health statistics 2010: World Health Organization; 2010.

[7] Black RE, Cousens S, Johnson HL, et al. Global, regional, and national causes of child mortality in 2008: a systematic analysis. Lancet 2010; 375: 1969-87

[8] Duke T, Yano E, Hutchinson A, Hwaihwanje I, Aipit J, Tovilu $\mathrm{M}$, et al. Large-scale data reporting of paediatric morbidity and mortality in developing countries : it can be done. 2015; $1-6$.

[9] George IO, Tabansi PN. An audit of cases in the children emergency ward in a Nigerian Tertiary Tospital. Pak J Med Sci 2010; 26: 740-3.

[10] Abhulimhen-Iyoha BI, Okolo AA. Morbidity and mortality of childhood illnesses at the emergency paediatric unit of the University of Benin Teaching Hospital, Benin city. Niger J Paediatr 2012; 39: 1-74.

[11] So O, Ao F, Oa O, Oa O. Pattern of childhood morbidities and outcome of childhood admissions in a Nigerian public secondary healthcare facility. 2018; 4 (2): 162-73.

[12] Toma BO, Gyang M, Abdu H, Shwe D, Ekere IA, Ihekaike M. Paediatric Morbidity and Mortality in a Suburban Hospital in Jos, North -Central Nigeria. 2015; 5 (2): 156-64.

[13] Anyanwu OU, Ezeanosike OB, Ezeonu CT. Pattern and outcome of admissions at the children emergency room at the Federal Teaching Hospital Abakaliki. 2014; 13 (1): 6-10.

[14] Bryce J, Boschi-Pinto C, Shibuya K, Black RE. WHO estimates of the causes of death in children. Lancet. 2005; 365: $1147-1152$.

[15] Fajolu I, Egri-Okwaji M. Childhood mortality in children emergency Centre of the Lagos University teaching hospital. Nigerian Journal of Paediatrics. 2011; 38 (3): 131-5.

[16] Molyneux E, Ahmad S, Robertson A. Improved triage and emergency care for children reduces inpatient mortality in a resource-constrained setting. Bull World Health Organ. 2006; 84: 314-9.

[17] Abebe T, Girmay M. The epidemiological profile of pediatric patients admitted to the general intensive care unit in an ethiopian university hospital. International Journal of General medicine. 2015; 8: 63.

[18] Okechukwu A, Nwalozie C. Morbidity and mortality pattern of admissions into the emergency Paediatric unit of University of Abuja Teaching Hospital, Gwagwalada. Nigerian Journal of Medicine: Journal of the National Association of Resident Doctors of Nigeria. 2011; 20: 109-13.

[19] Ikefuna AN, Emodi IJ. Some characteristics of Paediatric admission at the University of Nigeria Teaching Hospital Enugu Nigeria. Niger J Clin Pract 2007; 10: 216-9.

[20] George IO. Mortality Pattern in Children : A Hospital Based Study in Nigeria. 2009; 5 (4): 369-72.

[21] Bilkisu GI, Aminu MS, Sunday OO, Bassey E, Smart A, Muyideen AB. Original Article Pattern of medical childhood morbidity and mortality in a new specialist hospital in Gusau, Nigeria. 2014; 8 (1): 15-9.

[22] Adhikari J, Belbase M, Bahl L. Demographic Profile and Childhood Morbidity Pattern in Western Nepal. 2014; 12 (2): 20-3.

[23] Gordon DM, Frenning S, Draper HR, Kokeb M. Prevalence and Burden of Diseases Presenting to a General Pediatrics Ward in Gondar, Ethiopia. 2013; 59 (5).

[24] Chukwu BF, Chinawa JM, Ikefuna AN, Emodi IJ. Pattern and outcome of paediatric medical admissions at the University of Nigeria Teaching Hospital (UNTH), Ituku-Ozalla, Enugu: A five year retrospective review $(2007-2011)$. Niger J Paed. 2013; 40: 354-359.

[25] Mouneke UV, Ibekwe RC, Eke CB, Ibekwe MU, Chinawa JM. Mortality among paediatric inpatients in Mile 4 Mission hospital Abakaliki, south-eastern Nigeria: A Hospital retrospective study. Niger J Paed. 2013; 40: 259-263.

[26] Fetuga B, Ogunlesi T, Adekanmbi F, Olarewaju D, Olowu A. Comparative analyses of childhood deaths in Sagamu, Nigeria: implications for the fourth MDG. SAJCH. 2007; 1: 106-111.

[27] Nigeria Centre for disease control-Viral Haemorrhagic Fevers. [cited 2019 29th April]; Available from: http://ncdc.gov.ng/disease/info/V/

[28] Duru C, Peterside O, Akinbami F. Pattern and outcome of admissions as seen in the paediatric emergency ward of the Niger Delta University Teaching Hospital Bayelsa State, Nigeria. Niger J Paed. 2013; 40: 232-237. 